NAujoks, G., I. Zaspel and U. Behrendt (1999): Microorganisms acting in tissue cultures of black locust (Robinia pseudoacacia L.). Acta Horticulturae 530: 129-135.

Rathmacher, G., M. Niggemann, H. Wypukol, K. GebHARDT, B. ZiegEnhagen and R. BialozYT (2009): Allelic ladders and reference genotypes for a rigorous standardization of poplar microsatellite data. Trees - Structure and Function 23: 573-583.

RÉdeI, K., Z. Osváth-Bujtás and I. Balla (2002): Clonal approaches to growing black locust (Robinia pseudoacacia) in Hungary: a review. Forestry 75: 547-552.

ScHRÖcK, O. (1953): Beitrag zur Züchtung der Robinie (Robinia pseudoacacia). Der Züchter 23: 266-272.

Slavov, G. T., G. T. Howe, I. A. Yakovlev, K. J. Edwards, K. V. Krutovsky, G. A. Tuskan, J. E. Carlson, S. H. Strauss and W. T. AdAMs (2004): Highly variable SSR markers in Douglas-fir: Mendelian inheritance and map locations. TAG Theoretical and Applied Genetics 108: 873-880.

Surles, S. E., J. L. Hamrick and B. Bongarten (1990): Mating systems in open-pollinated families of black locust (Robinia pseudoacacia). Silvae Genetica 39: 35-40.

Van Oosterhout, C., W. F. Hutchinson, D. P. M. Wills and P. SHIPLEY (2004): MICRO-CHECKER: software for identifying and correcting genotyping errors in microsatellite data. Molecular Ecology Notes 4: 535-538.

Vosman, B., R. Cooke, M. Ganal, R. Peeters, P. Isaac and G. BREDEMEIJER (2001): Standardization and application of microsatellite markers for variety identification on tomato and wheat. Acta Horticulturae 546.

\title{
Microarray Analysis of Gene Expression in Triploid Black Poplar
}

\author{
By Baoquan Hu ${ }^{1)}$, Bin Wang ${ }^{1)}$, Chunguo Wang ${ }^{1)}$, Wenqin Song ${ }^{1)}$ and Chengbin Chen ${ }^{1), *}$
}

(Received $19^{\text {th }}$ November 2011)

\begin{abstract}
Triploidy is a widespread phenomenon in cultivated and natural breeding plants and it can confer some growth advantages. Here, we analyzed genome-wide gene expression in triploid Populus euramericana (black poplar) using the Affymetrix poplar microarray to detect any possible correlation between triploid vigor and a unique gene expression profile. Among the 38,400 transcripts that were detected in triploid poplar, 1,564 and 2,015 genes were up- or downregulated, respectively, compared with the diploid. The majority of the upregulated genes in the triploid were associated with carbon and nitrogen metabolism, especially lignin and secondary metabolism. Other genes upregulated in the triploid included genes involved in sugar transport, and brassinosteroid (BR) and auxin metabolism. Downregulated genes were mostly related to the assembly and biosynthesis of ribosomes and the nucleosome macromolecular complex. The results suggested that BR and auxin levels were crucial in controlling sugar transport, photosynthesis and cell wall biosynthesis. Downregulated genes were associated with chromatin regulation in the triploid. The information from this analysis could provide an insight into the vigor of triploid poplar.
\end{abstract}

Key words: Gene expression; Populus; microarray; triploid.

Abbreviations: BR, brassinosteroid; cRNA, complementary RNA; ESTs, expressed-sequence tags; GO, gene ontology; IAA,

1) College of Life Sciences, NanKai University, Tianjin 300071, People's Republic of China.

*) Corresponding author: ChengBin Chen. Tel.: +86 22 23508241, Fax: +86 22 23508241. E-Mail address: chchbin@126.com indole-3-acetic acid; qRT-PCR quantitative real-time polymerase chain reaction; SEA, singular enrichment analysis.

\section{Introduction}

Polyploidy is a widespread phenomenon in plants, and it is also a major mechanism driving speciation. Approximately $60-70 \%$ of flowering plants have undergone polyploidization during their ancestry (BLANC and Wolfe, 2004; CUI et al., 2006; MASTERSON, 1994), and it is estimated that $15 \%$ of angiosperm speciation has been achieved by polyploidization (RIESEBERG and WILLIS, 2007). However, new polyploids often face reproductive isolation from their progenitors due to the triploid reproductive barrier, which is caused by the production of unreduced gametes (KOHLER et al., 2010). Therefore, the plants that evolved by polyploidization remain in a triploid state. This speciation process has been defined as the triploid bridge, and is thought to play an important role in plant evolution (YAMAUCHI et al., 2004).

Triploidy is also found in natural plant groups, and these plants can have growth advantages. There exist triploid varieties in various species of poplar, including Populus tremula, Populus alba (PAuley, 1949), Populus balsamifera and Populus tremuloides (VAN BUIJTENEN et al., 1958). Compared with their diploid counterparts, the triploid trees are faster growing, have larger leaves and show greater vigor (LI et al., 2008). Several studies have examined triploid white poplar, which has good growth performance and other desirable properties (ZHANG et 
al., 2005; ZHANG et al., 2008; ZHENG et al., 2009). Triploids can be generated from crossings between the tetraploid and diploid or from unreduced gametes during normal crossing between diploids. For example, crosses between Populus trichocarpa and Populus deltoides from different geographic locations often produce triploid individuals in the first filial generation (BRADSHAW and STETTLER, 1993). The appearance of triploid in progenies is often related to evolutionary and ecological changes in plants (WU, 2000), and plants may benefit with increases in performance in response to environmental changes.

With the use of high-throughput microarray technologies, many studies have detected genome-wide expression changes in polyploid plants. Additive and non-additive expression changes have been observed in genes of allopolyploids in Arabidopsis, cotton and Senecio (JACKSON and CHEN, 2011), and between $30 \%$ and $95 \%$ of expressed genes were identified as additive in allopolyploids (Flagel et al., 2008; HEGARTY et al.. 2006; Pumphrey et al.. 2009; WANG et al., 2006). These gene expression changes in polyploids could result from the reunification of divergent genomes, which enables the possible combination of different transcription factors in a single regulatory network system (RIDDLE and BIRCHLER, 2003). The researchers argued that superior hybrid vigor may result from altered regulatory effects and the positive effects of an enlarged repertoire of regulatory responses, and this hypothesis was verified in Arabidopsis hybrids (ANDORF et al.).
However, relatively little is known with respect to global gene expression in triploid trees. In the present study, triploid black poplar (generated from crossing the maternal parent $P$. deltoides with the pollen parent Populus nigra) was used to investigate the gene expression profile in this triploid tree.

\section{Materials and Methods \\ Plant material and RNA extraction}

The offspring trees were generated 30-years ago from crosses between the maternal parent $P$. deltoides and the pollen parent $P$. nigra. Cuttings from offspring were grown in water culture for chromosomal preparation. Root tips that were approximately $1 \mathrm{~cm}$ long were collected and treated with a saturated aqueous solution of $\alpha$-bromonapthalene and paracide for 3 hours at room temperature and then fixed in Carnoy's fixative (ethanol: acetic acid $=3: 1, \mathrm{v} / \mathrm{v}$ ) for $1 \mathrm{~h}$. The fixed roots were spread on the slide in a water film by fine pointed forceps and air-dried. One triploid was identified from these cuttings. Cuttings from the triploid and a single diploid were transferred to the same field to grow for one year.

The first to third fully-expanded leaves (numbered from the apical bud) of the three triploids $(2 \mathrm{n}=3 \mathrm{x}=57)$ and three diploids $(2 \mathrm{n}=2 \mathrm{x}=38)$ of the black poplar (Populus euramericana cl. 'Zhonglin 46') were collected at the same time after growth under natural conditions. The leaves were stored immediately in liquid nitrogen.

Table 1. - The oligonucleotides used in Quantitative RT-PCR.

\begin{tabular}{|c|c|c|c|}
\hline II) & GenRank ID. & Forward primer & Reverse primer \\
\hline $18 \$$ & * & 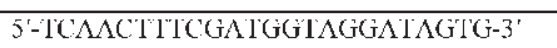 & $5^{\prime}$-COGIGICAGGALTGGGLAMIII-3' \\
\hline $\mathrm{AC}[$ & (GQ339771.1 & 5 -CCACGAGAC TACATACAAC TCAATC-3r & $5^{\prime}$-TCTCCI"IGCTCATICGGiTCA-3' \\
\hline G3pdlı & FJ581064.1 & 5'GATGGGAAGTTGACTGGAATGT-3' & $5^{\prime}$-GCGCCTTACTTGATAGCAGATT-3' \\
\hline Lbi & A 1240445.1 & $5^{\circ}-G G A A C G G G I I G A G G A G A A A G-3^{\prime}$ & 5'-GCAAGAACAAGAIGAAGCACAG-3' \\
\hline MTIb & AY594296.1 & 5'-АGTTGAGTTAGGCTTGAGCAGAT-3' & 5'-TCTCGGTTGTGGTGCTCTCT-3' \\
\hline IYFR & AY 147903.1 & $5^{\circ}-\mathrm{GCAAC} \mid \mathrm{CGOA} / \mathrm{GA} / \mathrm{GClAACA}-3^{\prime}$ & 5'-1' 'TGGAlGAGAAAGCAACACAC-3' \\
\hline Ispl & AY 438099.1 & 5'GCICGIGIGATIGATGIJGRI-3' & 5'-TGGCACAGGATCAAIGAGIAGAG-3' \\
\hline VSP & $\Lambda F 330050.1$ & 5-TGCCAATAGAIICANGGCAC-3. & $\left.5^{\prime}-C G M M\right] \Lambda G C A C G G A N A M G A T-3$ \\
\hline $\mathrm{Cl} 35$ & CA.821322.1 & 5'CACGCII"ICAATGAGGCAGAC-3' & 5'-ACCAGIAAACAC TAAIGGCAGGAC-3' \\
\hline AVR & CV271220.1 & 5'CAACCTAGAATATCTCCGCAGTC-3' & 5'-GAAGAGACCTATGACCAAACTGTG-3' \\
\hline GASA & CV247388.1 & 5'ACCTCCTCGTGCATTGTGAT-3r & 5'-CAAACC TGGITGTGGCATC-3 \\
\hline MT & AJ698935.1 & 5-TGGAAGCGATTCGGCATTA-3' & 5'-TCACCGCANCCTGACAGATG-3' \\
\hline $\mid \mathrm{lST}-1$ & CK090151.1 & $5^{\prime}-\mathrm{Cl}^{\prime} \mathrm{AACAAGCCACGACCACAG-3^{ \prime }}$ & $5^{\prime}$-CCCTCAAATCAAATC"TCCTCTC-3' \\
\hline ANS & CV264096.1 & 5'TGGTGCCTGGTCTAC МАCTCTT-3' & $5^{\prime}-\triangle A A C T G C C C A T G A A A T C C T T A C-3^{\prime}$ \\
\hline KUN & (V) 281016.1 & 5 -GACCACAGGAGIGTGTTGATAGATT-3' & $5^{\prime}$-TTCACAGAAGGGTTCGGACiTT-3 \\
\hline
\end{tabular}

*: The 18S primer was from Meng's works. M. Meng, M. Geisler, H. Johansson, E. J. Mellerowicz, S. KarPINSKI, L.A. KLECZKOwSKI, Differential tissue/organ-dependent expression of two sucrose- and cold-responsive genes for UDP-glucose pyrophosphorylase in Populus, Gene, 389 (2007) 186-195. 
Total RNA was extracted according to Kiefer's method (KIEFER et al., 2000) from three individuals. RNA samples were treated with DNase I (TaKaRa, Japan) and checked for purity on a $1.5 \%(\mathrm{w} / \mathrm{v})$ agarose/formal dehyde gel.

\section{Microarray analysis}

The two total RNA sample pools were equivalently mixed by three individual diploids and triploids for Affymetrix Poplar Genechip arrays. A One-Cycle cDNA Synthesis kit (Affymetrix, USA) was used to generate

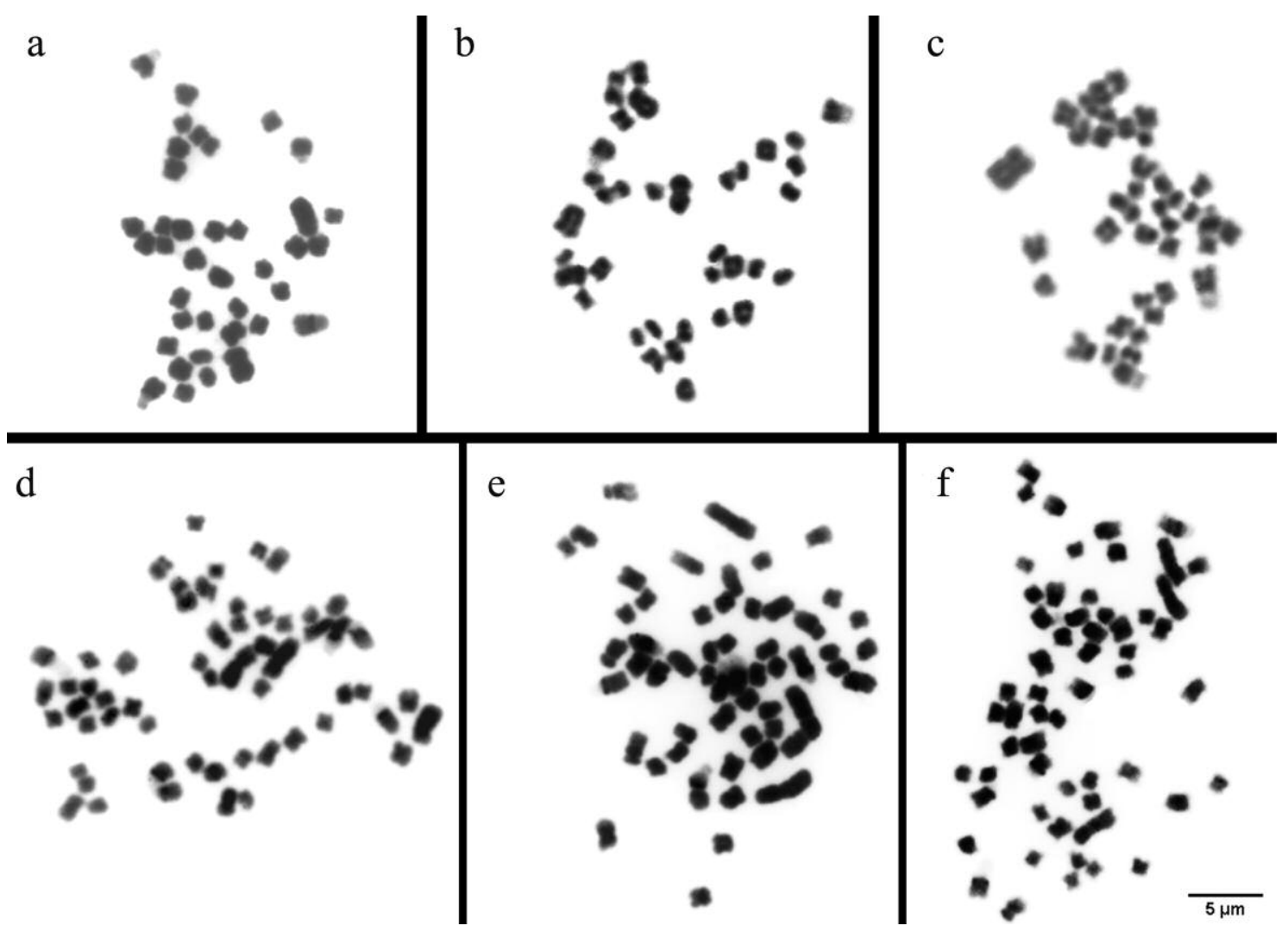

Figure 1. - Chromsome analysis of Populus euramericana. a-c, diploid black poplar $(2 \mathrm{n}=2 \mathrm{x}=38)$; $\mathrm{d}-\mathrm{f}$, triploid black poplar $(2 \mathrm{n}=3 \mathrm{x}=57)$. Scale bar, $5 \mu \mathrm{m}$.

Table 2. - The selected genes analyzed by qRT-PCR.

\begin{tabular}{clll}
\hline ID & Gene name & GenBank ID. & Expected size \\
\hline MTlb & Metallothionein Ib & AY594296.1 & -2.05 \\
DFR & Dihydroflavonol 4-reductase & AY147903.1 & 5.42 \\
Tspl & (-)-germacrene D synthase & AY438099.1 & 5.72 \\
VSP & Vegetative storage protein & AF330050.1 & 5.1 \\
CBS & Similar to cytochrome b5-like heme/ steroid binding domain protein & CA821322.1 & 10.91 \\
A.NR & Similar to anthocyanidin reductase & CV271220.1 & 7.63 \\
GASA & Similar to GASA4 (Gastl protein homolog 4) & CV247388.1 & 7.11 \\
MI & Similar to monosaccharide transporter & A.J698935.1 & 6.28 \\
ES'I-I & Predicted protein & CK090151.1 & -20.87 \\
AVS & Similar to anthocyanidin synthase & CV264096.1 & 71.63 \\
KIIV & Similar to kunitz-type protease inhibitor KPI-B5 & CV281016.1 & 78.87 \\
\hline
\end{tabular}


double-stranded cDNAs using SuperScript II (Invitrogen, USA) with T7-Oligo (dT) primers. The Sample Cleanup Module (Affymetrix, USA) was employed to purify the cDNAs, and then an IVT Labeling kit (Affymetrix, USA) was used to biotin-label the targets to generate complementary RNAs (cRNAs). The cRNAs were purified again and fragmented. The length of cRNAs ranged from 35 to 200 nucleotides. The cRNAs were hybridized in a Hybridization Oven 640, and then the arrays were washed and stained on an Affymetrix GeneChip Fluidics Station 450. Finally, a GeneChip ${ }^{\circledR}$ Scanner 3000 (CapitalBio Corp., China) was used to collect the signal from the arrays. The one-sided Wilcoxon's rank test was performed to determine the call of each transcript: P (present), M (marginal) or A (absent). The fold-changes in the expression of each transcript were calculated from the ratio of the signal values from the triploid and diploid samples. If the signal value was greater in the triploid, the fold-change was calculated from the triploid: diploid ratio; otherwise the foldchange was calculated from the diploid: triploid ratio. Genes with fold changes $>2.0$ were identified as differentially expressed. Singular enrichment analysis of the detected genes were performed using AgriGO software (Du et al., 2010), and statistical strategies were the employed using the Hypergeometric method with Yeku- tieli's method for multiple test corrections to compare the common genes for each GO term.

\section{Quantitative real-time PCR ( $q R T-P C R)$}

Extraction of total RNA was carried out as above and digested by DNase I (TaKaRa, Japan) to avoid interference by DNA. The first-strand cDNAs were synthesized by using equal quantities of total RNA with oligo $(\mathrm{dT})_{15}$ and M-MLV reverse transcriptase (Promega, USA). The quantities of synthesized cDNAs were determined using a NanoDrop ND-1000 (Nanodrop Technologies, Germany), and then concentrations were adjusted to $200 \mathrm{ng} \cdot \mu \mathrm{L}^{-1}$. qRT-PCR was performed with FastStart SYBR Green Master (Roche, Germany) using a Bio-Rad MyiQ Thermal Cycler (Bio-Rad, USA). The $25 \mu \mathrm{L}$ reaction volumes contained $1 \times$ FastStart SYBR Green Master, $0.2 \mu \mathrm{M}$ of each primer and $500 \mathrm{ng}$ of cDNA. The program employed a three step method: $94^{\circ} \mathrm{C}$ for $2 \mathrm{~min}$, followed by 45 cycles of $95^{\circ} \mathrm{C}$ for $15 \mathrm{~s}, 60^{\circ} \mathrm{C}$ for $30 \mathrm{~s}$, and $72^{\circ} \mathrm{C}$ for 30 s. Four housekeeping genes $(A C T$, G3pdh, Ubi, 18S) were selected as the combined references (Table 1) to normalize expression levels using the BioRad Optical System software (version 2.0). The gene expression profiles of three diploid and triploid individuals were analyzed three times.

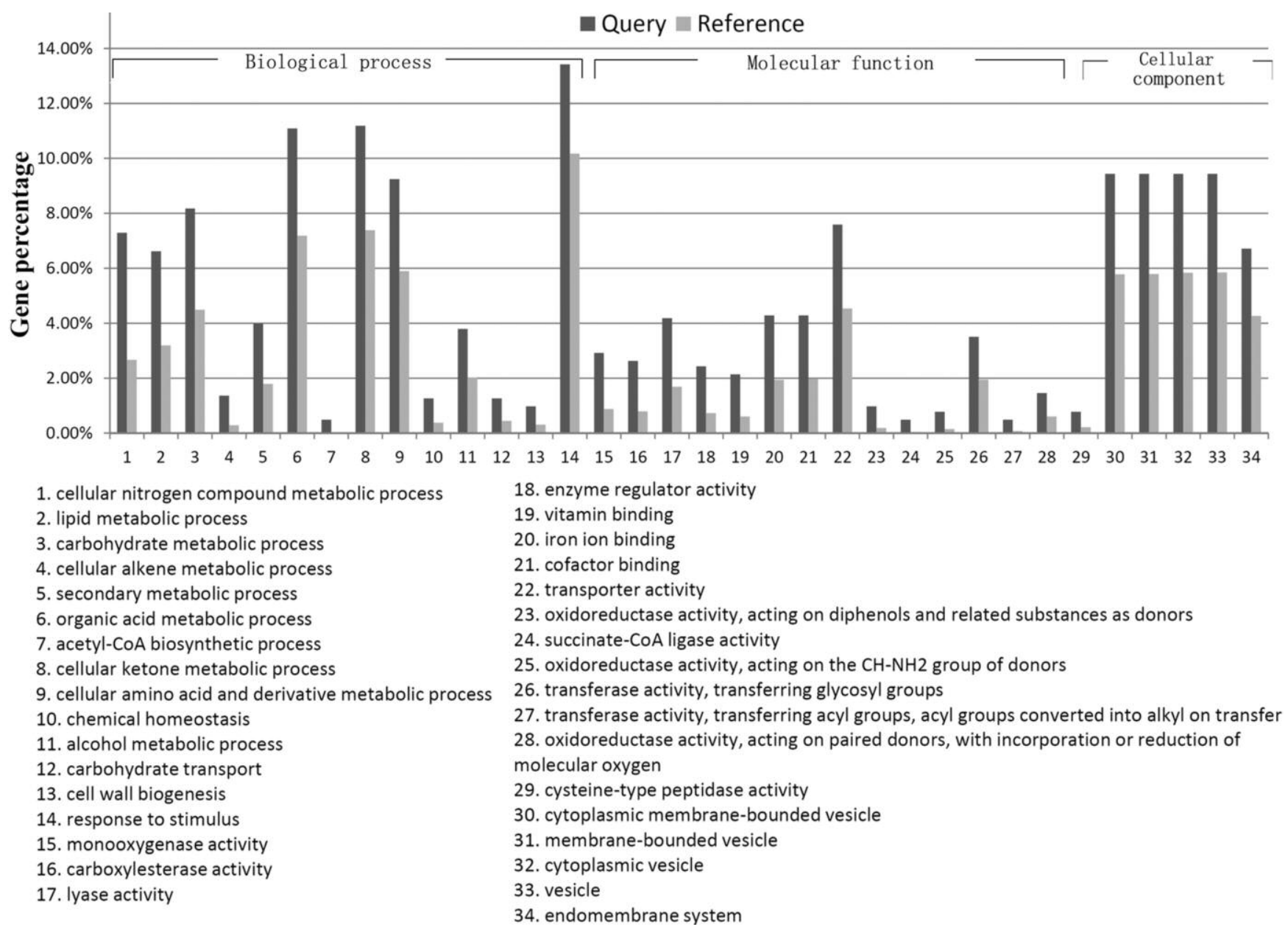

Figure 2. - The percentages of genes in each enrichment of significant GO terms were occupied in all upregulated genes queried in triploid P. euramericana. Genes in the triploid were assigned in ascending order according to the p-value. 


\section{Results}

Chromosome analysis of diploid and triploid

P. euramericana

The polyploid levels of black poplar clones were identified by counting chromosome numbers in root cells. The results indicated that our materials were stable diploids and triploids among several analyses (Figure 1). Chromosome aberrations were not observed in triploid black poplar.

\section{Global gene expression in triploid P. euramericana}

The GeneChip ${ }^{\circledR}$ Poplar Genome Array with 61,251 poplar probe sets was employed to detect overall gene expression in the triploid poplar. In total, 56,055 transcripts were interrogated on the array when considering UniGene clusters, expressed-sequence tags (ESTs) and mRNAs, predicted gene transcripts, poplar controls, and rRNAs. RNA expression levels were calculated using the GeneChip ${ }^{\circledR}$ operating software (Affymetrix, version 1.4). A total of 38,400 transcripts were detected in the diploid and triploid P. euramericana. Thus, $9.32 \%$ of the 38,400 transcripts were differentially expressed and these were selected for further analysis. In all, 1,564 and 2,015 genes were up- and downregulated in the triploid $P$. euramericana respectively, compared with the diploid.
Singular enrichment analysis (SEA) of the detected expression gene

Gene annotations were obtained from Affymetrix, and genes were sorted according to Gene Ontology (GO; Complete GO, version 2010-03-11) (Figures 2-4). In the triploid, 151 and 94 significant GO terms were found in the up- and downregulated genes, respectively (significance level $\mathrm{p}<0.05$ ).

\section{Metabolic genes}

As expected, triploid leaves were enriched for transcripts associated with metabolism (Figure 2), such as glutamate decarboxylase, ATP-citrate synthase, longchain acyl-CoA synthetase, and trans-cinnamate 4hydroxylase, when compared with the diploids. Overall, young leaves had a higher expression of genes involved in nitrogen compound metabolism, carbohydrate metabolism and lipid metabolism, and particularly amino acid metabolism and amino acid derivative metabolism. Moreover, triploid-preferred expression was detected for several genes involved in glutamine and aspartate metabolism, which were strongly involved in the regulation of a compound metabolic network that links nitrogen assimilation with carbon metabolism in young plants, which potentially reflects the presence of unique

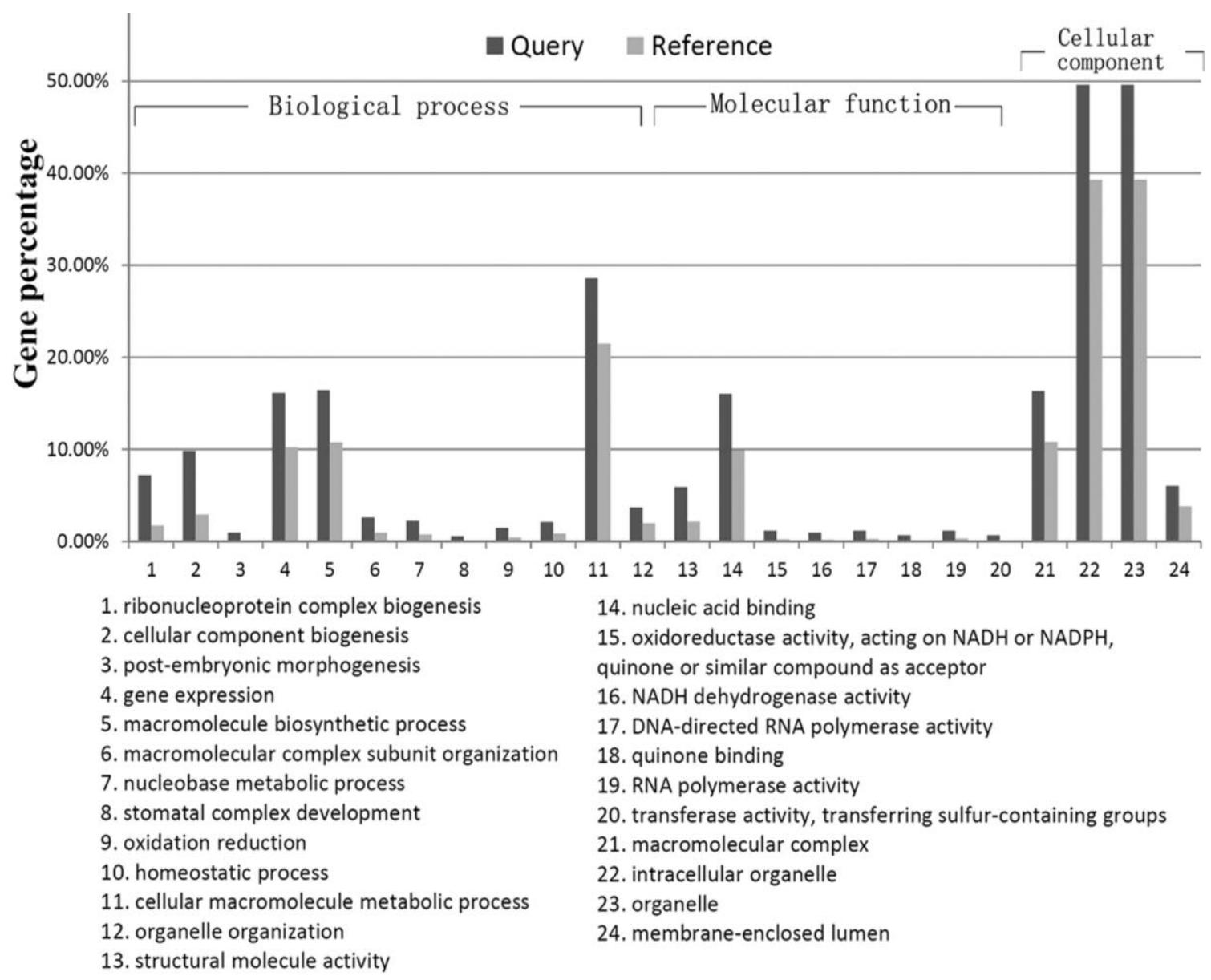

Figure 3. - The percentages of genes in each enrichment of significant GO terms were occupied in all downregulated genes queried in triploid P. euramericana. Genes in the triploid were assigned in ascending order according to the $p$-value. 
Table 3. - Upregulated genes related with cellulose biosynthesis and organization.

\begin{tabular}{|c|c|c|c|}
\hline Probe ID & Transcript ID & Expression levels & Gence name \\
\hline PtpAffx.129001.1.S1_at & GicnBank ID): CN523759 & 2.16 & Similar to cellulose synthase A \\
\hline Ptp $\Lambda$ ffx.26689.2.S1_at & GenBank ID): All63264 & 2.75 & $\begin{array}{l}\text { Similar to mannose-1 -phosphate } \\
\text { guanylyltransferabe/ nucleotidyltransferabe }\end{array}$ \\
\hline Ptp.666.1.S1_at & GenBank L): $\Lambda Y 573571$ & 2.17 & Cellulose synthase (Ces $A l)$ \\
\hline Ptp.3087.1.51_at & GenBank ID: A.T778410 & 2.24 & Similar to cellulose synthase \\
\hline PtpAffx.216899.1.S1_sat & $\begin{array}{l}\text { JGI ID: gw1.155.39.1, } \\
g w 1.155 .46 .1\end{array}$ & 2.19 & COBRA-liks protein \\
\hline I'tp,274.1.S1_at & Gen1Bar1k II): AY935505 & 2.95 & $\begin{array}{l}\text { Cell wall-related glycosyltransferase family } \\
43\end{array}$ \\
\hline
\end{tabular}

Table 4. - Upregulated genes related with hormone biosynthesis and transport.

\begin{tabular}{|c|c|c|c|}
\hline \multicolumn{2}{|c|}{ Expression levels } & \multirow{2}{*}{$\begin{array}{l}\text { Transcript ID } \\
\text { JGI ID:estExt_fgenesh4_pg.C_640031 }\end{array}$} & \multirow{2}{*}{$\begin{array}{l}\text { Gene name } \\
\text { Aminopeptidase }\end{array}$} \\
\hline PtpAffx.222225.1.S1_at & 2.08 & & \\
\hline PtpAffx.209283.1.S1_at & 2.52 & JCil ID: grail3.0022014001 & Cytochrome P450 (CYP90A6v1) \\
\hline 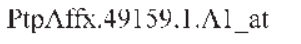 & 2.02 & GenBank $\amalg$ : CX180149 & Auxin efflux cartier family protein \\
\hline PtpAffx.28783.I.S1_s_at & 2.25 & GenBank ID: DN501860 & Cytochrome P450 (CYP90D5) \\
\hline PtpAffx.69346.1.Al_at & 2.17 & GenBank ID: CV260517 & IAA-amino acid hydrolase 8 \\
\hline Ptp $\Lambda$ ffi.68843.1.S1_at & 3.51 & GenBank II): C V 282778 & Muxin:hydrogen symporter \\
\hline PtpAffx.209682.1.S1_al & 2.88 & JGI ID: grwl.XI.1757.1 & Trptophan synthase \\
\hline PipAffx.59155.1.51_s_al & 2.49 & Genl3ank II): I) V499235 & Aminopeptidase \\
\hline I’tp.5500.1.S1_at & 2.01 & Gonbank II): I)V492580 & Spermine synthase \\
\hline PIpAlfx.82668.1.A1_at & 2.89 & GenBank ID: CV237904 & $\begin{array}{l}\text { Cylochrome P450 (CYT79D7) tyrosine } \\
\text { V-hydroxylase }\end{array}$ \\
\hline I’tpAffx,219829,1.S1_at & 2.7 & $J G \mid \Gamma 1) ;$ eugene3,00280341 & Auxin eftlux carrier component \\
\hline PtpAlfx.60955.1.S1_s_al & 2.0 & GenBank ID: DN502052 & Cylochrome P450 (CYP90Ds) \\
\hline
\end{tabular}

carbon and nitrogen cycling processes in triploid black poplar.

\section{Cell wall biosynthesis}

Triploid leaves differed significantly from diploid leaves with regards to genes that encode enzymes involved in cell wall biosynthesis, such as secondary cell wall-related glycosyltransferase, cellulose synthase and alpha-1,2-fucosyltransferase. Genes related to sugar transporters were also preferentially expressed in triploid leaves. Leaves showed a higher abundance of RNAs for phenylpropanoid metabolism and lignin biosynthesis-related genes. The same was observed in the other downstream pathway of phenylpropanoid metabolism (coumarin and flavonoid biosynthesis). 
Regulation network

Triploid leaves presented a higher mRNA abundance for genes involved in stimulus response, such as salt, metal ions and cold. Several proteins encoding these response genes also simultaneously participated in the regulation of hormone biosynthesis and transport. For example, a gene encoding the transcription repressor, MYB6, was involved in the abscisic acid, salicylic acid, jasmonic acid, ethylene and gibberellin pathways. Moreover, a relatively small set of genes (13) related to chemical homeostasis was detected as triploid-preferred in triploid leaves. mRNA abundance profiles of genes involved in the response to stimulus and chemical homeostasis possibly resulted from the combination of divergent regulatory factors from different genomes.

\section{Downregulated genes}

Lowly expressed triploid-preferred genes were mainly involved in ribosome and nucleosome macromolecular complex assembly and biosynthesis (Figure 3). In addition, triploid leaves presented a lower mRNA abundance for genes associated with gene expression and the nucleobase metabolic process. A few oxidation-reduction genes involved in electron transport in the chloroplast and mitochondrion were also expressed at low levels in the triploid. Overall, young leaves had a lower expression level of genes related to cellular components involved with genetic material.

\section{qRT-PCR of selected genes}

qRT-PCR was employed to verify the microarray expression data in three diploid and triploid clones for 11 differentially expressed transcripts (Table 2). The 11 transcripts were randomly selected from those with a high to low fold change. Melt curve analysis after each reaction showed only one peak. The relative expression ratios were calculated using the $2^{-\Delta \Delta \mathrm{Ct}}$ method. The expression levels of 8 transcripts were similar to or higher than the results from microarray, while the expression trends of the other three transcripts were in accordance with the microarray data (Figure 4). The expression trends of these genes did not differ from the expression in the microarray analysis, although the relative expression ratios of several genes differed in terms of numerical abundance. Thus, the qRT-PCR data confirmed the expression profiles determined in the microarrays.

\section{Discussion}

Rapid and dynamic changes in gene expression in plant polyploids using high-throughput technologies have been described for numerous plants, including cotton, wheat, maize and Arabidopsis (JACKSON and CHEN, 2010). In this study, the poplar genome microarray was used to detect gene expression levels in young leaves of triploid black poplar. A homologous diploid poplar was used to normalize the gene expression levels in the triploid and this enabled the identification of 3,579 differentially expressed genes within a total of 38,400 . The up- and downregulated genes were classified into different gene categories and grouped according to GO.
The upregulated genes were concerned with various types of primary and secondary metabolism. In polyploid Arabidopsis, 25\% of differentially expressed genes are involved in metabolism (WANG et al., 2006). This enhancement of metabolism is generally thought to explain the improved morphological vigor of polyploidy plants. In the present study, carbon and nitrogen cycling processes (including amino acid and carbohydrate metabolism, and organic and carboxylic acid catabolism) were significantly reinforced in the triploid poplar, which could manifest as more rapid growth and greater accumulation of biomass.

The transcript abundance of genes related to phenylpropanoid biosynthesis were significantly increased in the triploid poplar (Figure 2). Lignin is the major product of phenylpropanoid metabolism and it is a key structural component of cell walls. Genes involved in lignin metabolism and biosynthesis were upregulated in the triploid poplar. In an earlier study, suppression of lignin biosynthesis was shown to increase cellulose biosynthesis and plant growth (WEI et al., 2005). But the reduction in lignification simultaneously increased the cellulose content in wood and the xylem's vulnerability to embolism (WEI et al., 2005). This present study suggests that lignin biosynthesis in poplar contributes greatly to plant growth (HANCOCK et al., 2007). Indeed, the downregulation of a gene in the phenylpropanoid pathway (4coumarate: coenzyme A ligase) has been shown to reduce significantly poplar growth efficiency (VOELKER et al., 2011a; 2011b). Moreover, transgenic poplar containing the ferulate- 5 hydroxylase gene (which is also involved in phenylpropanoid metabolism) contains more solid wood than the wild type (HuNTLEY et al., 2003). In our microarray analysis, the genes related to cellulose metabolism and cellulose microfibril organization were upregulated (Table 3). The enhancement of the lignin and cellulose metabolism together may play an important role in improving the growth and morphological vigor of the triploid poplar. Other researchers have suggested that natural lignin contents have evolved to the most suitable condition (VoELKER et al., 2011b). The results of the present study demonstrate that activation or suppression of a single metabolic pathway in cell wall biosynthesis may limit improvements in plant growth, and the most efficient method to promote growth is to coordinately manipulate gene expression in both lignin and cellulose metabolism.

The polymer trap model proposes that sucrose (the major transported sugar in poplar) is carried out of the leaves to reduce sucrose concentrations and converted into raffinose-family oligosaccharides; otherwise the accumulation of sucrose in leaves would inhibit photosynthesis (MCCASKILL and TURGEON, 2007; TURGEON and Gowan, 1990; Turgeon and BeEBE, 1991). Genes involved in carbohydrate metabolic processes and transport (Figure 2) were significantly upregulated in triploid black poplar. The activation of sugar transport has been detected in other polyploids in previous studies (CHEN, 2010; LlOYD et al., 2005; SMITH et al., 2005), and more starch has been shown to accumulate in polyploid plants. Sucrose transport drives the partition of photosynthesis products between the biomass source and sink 
(Ainsworth and Bush, 2011; Ayre, 2011; Liesche et al., 2011). Timely sucrose transport out of the leaves in the triploid black poplar probably maintained a high efficiency of photosynthesis, and therefore promotes increase in biomass.

Small changes in the expression of key genes are important in regulatory systems (HUANG DA et al., 2009). Some genes involved in regulating hormone levels, transport and biosynthesis were upregulated in triploid black poplar (Table 4), including a tryptophan synthaselike gene. The product of this gene catalyzes the last two steps of the synthesis of tryptophan, which is vital for indole-3-acetic acid (IAA) synthesis (DUNN et al., 2008). Furthermore, genes encoding proteins like the auxin efflux carrier family protein and aminopeptidase, which are involved in regulating auxin transport (MURPHY et al., 2002), were also upregulated in triploid black poplar. These results suggest that IAA synthesis, transport and concentration regulation were enhanced in the triploid tree.

The cytochrome P450-like genes involved in brassinosteroids (BRs) biosynthesis, such as CYP90D, CYP90A6v1, were detected in the upregulated genes of triploid poplar. The important oxidative reactions in the synthesis of BRs are processed by the cytochrome P450 CYP90 and CYP85 families of enzymes (BANCOs et al., 2002). BRs can improve photosynthetic parameters and plant growth (XIA et al., 2009). In transgenic plants expressing the cytochrome P450 family protein, C-22 hydroxylase (which controls BRs levels), increases in BRs were shown to promote the flow of photosynthetic products from source to sink (Wu et al., 2008). Therefore, the increase in BRs probably originated from the upregulation of cytochrome P450 family genes that are responsible for active sucrose transport in the triploid poplar. In addition, interactions and coordination between BRs and auxin have been reported in previous studies (BAO et al., 2004; DE GRAUwE et al., 2005; HALLIDAY, 2004; Li et al., 2005), and auxin related genes are also involved in cell wall biosynthesis (ANDERSSONGunNERAs et al., 2006). Moreover, sterols greatly contribute to the organization of plant cell biosynthesis (SCHRICK et al., 2004). Therefore, the interplay between these compounds may be important for cell wall biosynthesis and developmental regulation in the triploid black poplar.

The downregulated genes in the triploid poplar were mostly concerned with cellular components associated with genetic material, including the nucleosome, chromatin and ribosomes. The results indicated reduced chromatic agglutination in the triploid, which suggests that gene expression changes were related to chromatin regulation. Such changes may result in variations in hormone biosynthesis.

In summary, this study used microarray technology to analyze gene expression of triploid $P$. euramericana, and it was found that genes involved in carbon and nitrogen cycling metabolism were upregulated, which probably results in increases in biomass and photosynthetic efficiency. High photosynthetic efficiency probably results from an accelerated rate of sugar transport. Meanwhile, higher levels of BRs and auxin in the triploid poplar stemmed from the upregulation of genes involved in their biosynthesis and regulation. These hormones can promote sugar transport, photosynthesis and cell wall biosynthesis. Downregulated genes in the triploid poplar were involved in macromolecular complex assembly and biosynthesis and chromatin regulation. This present study is the first to report global gene expression data for triploid poplar, and provides an insight into the molecular mechanisms of triploid vigor and plasticity. Nevertheless, further studies are needed to investigate the key genes that regulate cellular metabolism in triploid poplar.

\section{Acknowledgements}

This research was supported by the grants from the National Basic Research Program of China (973 Program, Grant No. 2009CB119105), and Tianjin Province Natural Science and Technology Program of China (Grant No. 07CYBJC11700).

\section{References}

Andorf, S., J. Selbig, T. Altmann, K. Poos, H. WituckaWALL and D. REPSILBER (2010): Enriched partial correlations in genome-wide gene expression profiles of hybrids (A. thaliana): a systems biological approach towards the molecular basis of heterosis. Theor Appl Genet 120 (2): 249-259.

Ainsworth, E. A. and D. R. Bush (2011): Carbohydrate export from the leaf: a highly regulated process and target to enhance photosynthesis and productivity. Plant Physiol 155: 64-69.

Andersson-Gunneras, S., E. J. Mellerowicz, J. Love, B. Segerman, Y. Ohmiya, P. M. Coutinho, P. Nilsson, B. Henrissat, T. Moritz and B. Sundberg (2006): Biosynthesis of cellulose-enriched tension wood in Populus: global analysis of transcripts and metabolites identifies biochemical and developmental regulators in secondary wall biosynthesis. Plant J 45: 144-165.

Ayre, B. G. (2011): Membrane-Transport Systems for Sucrose in Relation to Whole-Plant Carbon Partitioning. Mol Plant. doi: 10.1093/mp/ssr014.

Bancos, S., T. Nomura, T. Sato, G. Molnar, G. J. Bishop, C. Koncz, T. Yokota, F. NAGY and M. Szekeres (2002): Regulation of transcript levels of the Arabidopsis cytochrome p450 genes involved in brassinosteroid biosynthesis. Plant Physiol 130: 504-513.

Bao, F., J. Shen, S. R. Brady, G. K. Muday, T. Asami and Z. YANG (2004): Brassinosteroids interact with auxin to promote lateral root development in Arabidopsis. Plant Physiol 134: 1624-1631.

Blanc, G. and K. H. WolFE (2004): Widespread paleopolyploidy in model plant species inferred from age distributions of duplicate genes. Plant Cell 16: 1667-1678.

Bradshaw, H. D. and R. F. Stettler (1993): Molecular genetics of growth and development in Populus. I. Triploidy in hybrid poplars. TAG Theoretical and Applied Genetics 86: 301-307.

Chen, Z. J. (2010): Molecular mechanisms of polyploidy and hybrid vigor. Trends Plant Sci 15: 57-71.

Cui, L., P. K. Wall, J. H. Leebens-Mack, B. G. Lindsay, D. E. Soltis, J. J. Doyle, P. S. Soltis, J. E. Carlson, K. Arumuganathan, A. Barakat, V. A. Albert, H. Ma, 
and C. W. DEPAMPHILIS (2006): Widespread genome duplications throughout the history of flowering plants. Genome Res 16: 738-749.

De Grauwe, L., F. Vandenbussche, O. Tietz, K. Palme, and D. Van Der Straeten (2005): Auxin, ethylene and brassinosteroids: tripartite control of growth in the Arabidopsis hypocotyl. Plant Cell Physiol 46: 827-836.

Du, Z., X. Zhou, Y. Ling, Z. Zhang and Z. Su (2010): agriGO: a GO analysis toolkit for the agricultural community. Nucleic Acids Res 38: W64-70.

DunN, M. F., D. NiKs, H. NGo, T. R. Barends, and I. Schlichting (2008): Tryptophan synthase: the workings of a channeling nanomachine. Trends Biochem Sci 33 : 254-264.

Flagel, L., J. Udall, D. Nettleton and J. Wendel (2008): Duplicate gene expression in allopolyploid Gossypium reveals two temporally distinct phases of expression evolution. BMC Biol 6: 16.

HALLIDAY, K. J. (2004): Plant hormones: the interplay of brassinosteroids and auxin. Curr Biol 14: R1008-1010.

Hancock, J. E., W. M. Loya, C. P. Giardina, L. Li, V. L. Chiang and K. S. Pregitzer (2007): Plant growth, biomass partitioning and soil carbon formation in response to altered lignin biosynthesis in Populus tremuloides. New Phytol 173: 732-742.

Hegarty, M. J., G. L. BARKeR, I. D. Wilson, R. J. ABbott, K. J. EdwARDS and S. J. Hiscock (2006): Transcriptome shock after interspecific hybridization in senecio is ameliorated by genome duplication. Curr Biol 16 (16): 1652-1659.

Huang, W., B. T. Sherman and R. A. Lempicki (2009): Bioinformatics enrichment tools: paths toward the comprehensive functional analysis of large gene lists. Nucleic Acids Res 37: 1-13.

Huntley, S. K., D. Ellis, M. Gilbert, C. Chapple and S. D. MANSFIELD (2003): Significant increases in pulping efficiency in $\mathrm{C} 4 \mathrm{H}-\mathrm{F} 5 \mathrm{H}$-transformed poplars: improved chemical savings and reduced environmental toxins. J Agric Food Chem 51: 6178-6183.

JACKSON, S. and Z. J. ChEN (2010): Genomic and expression plasticity of polyploidy. Curr Opin Plant Biol 13: 153-159.

Kiefer, E., W. Heller and D. ERnst (2000): A simple and efficient protocol for isolation of functional RNA from plant tissues rich in secondary metabolites. Plant Mol Bio Rep 18: 33-39.

Kohler, C., O. Mittelsten Scheid and A. Erilova (2010): The impact of the triploid block on the origin and evolution of polyploid plants. Trends Genet 26: 142-148.

LI, L., J. XU, Z. H. XU and H. W. Xue (2005): Brassinosteroids stimulate plant tropisms through modulation of polar auxin transport in Brassica and Arabidopsis. Plant Cell 17: 2738-2753.

LI, Y. H., X. Y. KANG, S. D. WANG, Z. H. ZHANG and H. W. CHen (2008): Triploid Induction in Populus alba $\mathrm{x}$ P. glandulosa by Chromosome Doubling of Female Gametes. Silvae Genetica 57: 37-40.

Liesche, J., U. Krugel, H. He, I. Chincinska, A. Hackel and C. KUHN (2011): Sucrose transporter regulation at the transcriptional, post-transcriptional and post-translational level. J Plant Physiol 168 (12): 1426-33.

Lloyd, J. R., J. Kossmann and G. RITTE (2005.): Leaf starch degradation comes out of the shadows. Trends Plant Sci 10: 130-137.

MAsterson, J. (1994): Stomatal size in fossil plants: evidence for polyploidy in majority of angiosperms. Science 264: 421-424.
McCaskill, A. and R. Turgeon (2007): Phloem loading in Verbascum phoeniceum L. depends on the synthesis of raffinose-family oligosaccharides. Proc Natl Acad Sci USA 104: 19619-19624.

Murphy, A. S., K. R. Hoogner, W. A. Peer and L. Taiz (2002): Identification, purification, and molecular cloning of N-1-naphthylphthalmic acid-binding plasma membrane-associated aminopeptidases from Arabidopsis. Plant Physiol 128: 935-950.

Pauley, S. (1949): Forest-tree genetics research: Populus L. Econ Bot 3: 299-330.

Pumphrey, M., J. BaI, D. LaUdencia-ChingCuanco, O. ANDERSON and B. S. GILl (2009): Nonadditive expression of homoeologous genes is established upon polyploidization in hexaploid wheat. Genetics 181 (3): 1147-1157.

RIDDLE, N. C. and J. A. BIRCHLER (2003): Effects of reunited diverged regulatory hierarchies in allopolyploids and species hybrids. Trends Genet 19 (11): 597-600.

RIEseberg, L. H. and J. H. Willis (2007): Plant speciation. Science 317: 910-914.

Schrick, K., S. Fujioka, S. Takatsuto, Y. D. Stierhof, H. Stransky, S. Yoshida and G. Jurgens (2004): A link between sterol biosynthesis, the cell wall, and cellulose in Arabidopsis. Plant J 38: 227-243.

Smith, A. M., S. C. ZeEMAN and S. M. Smith (2005): Starch degradation. Annu Rev Plant Biol 56: 73-98.

TURGEON, R. and E. GowAN (1990): Phloem Loading in Coleus blumei in the Absence of Carrier-Mediated Uptake of Export Sugar from the Apoplast. Plant Physiol 94: 1244-1249.

Turgeon, R. and D. U. Beebe (1991): The Evidence for Symplastic Phloem Loading. Plant Physiol 96: 349-354.

van BuiJtenen, J. P, P. N. JoRANSON and E. DW. (1958): Diploid versus triploid aspen as pulpwood sources with reference to growth, chemical, physical, and pulping differences. TAPPI 41: 170-175.

Voelker, S. L., B. Lachenbruch, F. C. Meinzer and S. H. STRAUSs (2011a): Reduced wood stiffness and strength, and altered stem form, in young antisense 4CL transgenic poplars with reduced lignin contents. New Phytol 189: 1096-1109.

Voelker, S. L., B. Lachenbruch, F. C. Meinzer, P. Kitin and S. H. Strauss (2011b): Transgenic poplars with reduced lignin show impaired xylem conductivity, growth efficiency and survival. Plant Cell Environ 34: 655-668.

Wang, J., L. Tian, H. S. Lee, N. E. Wei, H. Jiang, B. Watson, A. Madlung, T. C. Osborn, R. W. Doerge, L. Comai and Z. J. Chen (2006): Genomewide nonadditive gene regulation in Arabidopsis allotetraploids. Genetics 172: 507-517.

WeI, T., A. NELSON and E. Johnson (2005): Increasing cellulose production and transgenic plant growth in forest tree species. J Forest Res 16: 67-72-72.

Wu, C. Y., A. Trieu, P. Radhakrishnan, S. F. KWoK, S. HaRris, K. Zhang, J. WANG, J. WAN, H. ZHAI, S. Takatsuto, S. Matsumoto, S. Fujioka, K. A. FeldMANN and R. I. PENNELL (2008): Brassinosteroids regulate grain filling in rice. Plant Cell 20: 2130-2145.

Wu, R. L. (2000): Quantitative genetic variation of leaf size and shape in a mixed diploid and triploid population of Populus. Genet Res 75: 215-222.

XiA, X.-J., L.-F. HuAng, Y.-H. Zhou, W.-H. MaO, K. ShI, J.-X. WU, T. AsAmI, Z. CHEN and J.-Q. YU (2009): Brassinosteroids promote photosynthesis and growth by enhancing activation of Rubisco and expression of pho- 